\title{
Conservação do bambu
}

\author{
SALIM SIMĀO \\ Livre-docente da E. S. A. "Luiz de Queiroz" — U.S.P.
}

INDICE

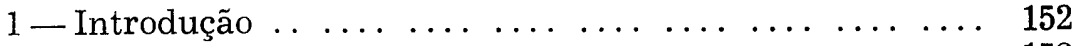

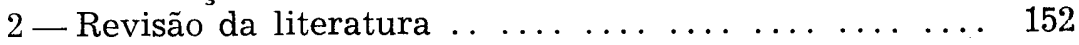

$\begin{array}{lllllllll}3-\text { Material e método } \ldots \ldots & \ldots & \ldots & \ldots & \ldots & \ldots & \ldots & \ldots & 155\end{array}$

4 - Discussão dos resultados $\ldots \ldots \ldots \ldots \ldots \ldots$

$\begin{array}{lllllllllll}5 & - \text { Conclusões } \ldots & \ldots & \ldots & \ldots & \ldots & \ldots & \ldots & \ldots & \ldots & \ldots\end{array}$

$\begin{array}{lllllllllll}6 \text { - Abstract } \ldots & \ldots & \ldots & \ldots & \ldots & \ldots & \ldots & \ldots & \ldots & \ldots & \ldots\end{array}$

$\begin{array}{llllllllll}7 \text {-Bibliografia } \ldots & \ldots & \ldots & \ldots & \ldots & \ldots & \ldots & \ldots & \ldots & \ldots\end{array}$ 


\section{1 - INTRODUÇÃO}

O bambu, planta largamente utilizada no meio agrícola e indústrial, pela sua crescente aplicação, vem dia a dia, ocupando maior destaque, entre as plantas cultivadas. Ponto que tem sempre suscitado controvérsia é o da sua durabilidade.

Conceitos vários apareceram sôbre as diferentes causas que contribuem para a rápida deterioração, principalmente estragos causados por insetos.

Um dos temas mais invocadus é a influência das fases da lua na época do corte, sôbre a durabilidade. Querem alguns atribuir a certas fases da lua o maior ou menor ataque por insetos, principalmente aquêle causado por brocas que perfuram e abrem galerias nos colmos.

Os pescadores só cortam os bambus para fazerem suas varas, na fase minguante e êste critério também tem sido seguido por inúmeras pessôas, com relação ao abate de árvores.

A fim de têrmos em mãos, dados que nos informassem a respeito da causa ou causas que influênciassem, sôbre o rápido desgaste do bambu, quer por ataques de insetos ou pelas condições climatéricas, realizámos o presente ensaio, com início em junho de 1947.

O nosso objetivo foi o de verificar a durabilidade do bambu, relacionando-a com os meses, fases da lua, estado de maturação, sanidade e consequente comportamento das estacas no campo ou em lugares abrigados.

Sendo o bambu matéria prima de primeira ordem, é justo que a êle dediquemos um pouco de atenção.

\section{2 - REVISÃO DA LITERATURA}

Inúmeros estudos sôbre o bambu, foram feitos por diferentes pesquisadores, com o fito de se determinar o desenvolvimento e a conservação relacionada com as influências lunares.

SIMÃO (1957), estudando o desenvolvimento do bambu, anotou um crescimento muito rápido, alcançando inicialmente 
$0,20 \mathrm{~m}$ por dia, levando o ciclo vegetativo de 90 a 120 dias. A paralização no desenvolvimento coincidia com a emissão das ramificações. Concluiu que para o aproveitamento em construções, quer internas ou externas, faz-se mister esperar o amadurecimento dos colmos, o que levaria de 5 a 10 meses. Nestas condições, correriam menos riscos de virem a ser atacadas por brocas e teriam sua durabilidade aumentada.

CAMUS (1913), reportou-se também ao crescimento exagerado dos bambus; a espécie $B$. tulda, em 30 dias alcançou $22 \mathrm{~m}$ e em Berlim registrou-se em um dia $0,22 \mathrm{~m}$ para o $B$. verticulata e $0,50 \mathrm{~m}$ para o B. gigantia.

TELES (1922), referindo-se à influência da lua no corta de madeira, diz ser forçado a aceitá-la como verdadeira, muito embora incorra na acusação de ser rotineiro ou supersticioso.

PUIG (1942), refere-se a opinião de MOREUX, o qual assevera que os botânicos, astrônomos e matereologistas negam fundamento à crença na ação da lua, classificando tal crença de prejudicial aos trabalhos agrícolas. Relata a opinião de AYMIE, que afirma nada ter a ver a broca de madeira com a fase da lua, no momento do corte da árvore. Faz um apêlo no sentido de que se realizem inúmeras experiências com critério científico, a fim de se comprovar ou não essa crença.

BEESON, (1946), referindo-se à data do corte da madeira e à sua durabilidade, diz que na Europa é crença generalizada que a madeira cortada na época da lua nova ou em sua fase minguante, é mais durável que cortada em outras fases. De 1669 até à Revolução Francêsa, leis gaulesas ordenavam que as árvores fossem cortadas somente dentro da fase minguante.

Acreditavam êles que havia redução de umidade nessa fase e daí a maior durabilidade e resistência. Para se analisar essa idéia, há necessidade de se estudar a suscetibilidade para o ataque de brocas, fungos e variação da resistência intrínseca de cada madeira. Sabe-se que o conteúdo de água varia para algumas espécies em certas estações e é constante em outras durante todo o ano.

O mesmo autor, relatando trabalho em cooperação com BATHIA, onde estudaram o conteúdo de umidade no colmo do Dendrocilamus Strictus, verificaram que a seiva aumentava 
da cheia para a nova e o decréscimo da nova para a cheia era aparente, mas não encontraram nenhuma variação significativa. Êstes resultados são contrários à crença popular, de que a seiva é mais abundante nos tecidos quando a fase da lua é cheia.

BEESON, ainda apreciando o trabalho de GARDNER, sôbre o contrôle da broca do bambu, diz que árvores cortadas nos trópicos, são expostas por muitos anos a ataque de brocas de diferentes espécies e cada uma delás necessita de condições ligeiramente distintas para oviposição e alimentação. Não era de se estranhar portanto, que os experimentos para determinar a proteção universal assinalada pela influência da lua dessem resultados negativos.

Experiências feitas pelo mesmo autor em Trinidad com Mora excelsa, não deram nenhuma correlação entre as fases da lua e danos causados por insetos e fungos.

PEREIRA (1949), com o objetivo de esclarecer no nosso meio a possibilidade de haver uma alteração da resistência natural da madeira correlacionada com os períodos lunares, iez sistemáticas observações do que ocorria, expondo em um insectário abundantemente povoado de Lyctus, material colhido em cada uma das fases lunares. A essência escolhida foi a Bauhinia forficata Link (unha de vaca) de lenho bastante apetecido pelos Lyctus.

A exposição dos corpos de prova variou de 12 a 37 semanas e ao fazer a observação constatou-se que não houve influência favorável da escolha de determinada lua para prevenir a incidência dos insetos. Justamente as amostras colhidas na fase minguante, foram nessa prova, as que mais depredações sofreram.

SIMÃO (1953), procurou determinar uma ação lunar sôbre os vegetais, principalmente hortaliças e não encontrou nenhum efeito das fases da lua, quer melhorando ou reduzindo o desenvolvimento e a produção. Em uma mesma cultura, intervêm quer aumentando ou diminuindo, fases da lua opostas em relação ao conceito generalizado. Verificou serem muito mais importantes as condições climáticas, tais como temperatura, umidade, chuva, insolação, do que alguma possível influência lunar. 


\section{3 - MATERIAL E MÉTODO}

Para o presente ensaio, utilizou-se a espécie Banbusa vulgaris, plantada nos terrenos da Secção Técnica de Horticultura da E. S. A. "Luiz de Queiroz". As touceiras de bambu aí existentes margeiam o curso do rio Piracicamirim, servindo a um só tempo de proteção ao solo, embelezamento e de materia prima para os trabalhos agrícolas. Os cortes foram efetuados, obedecendo-se às fases lunares. Para cada fase, cortavam-se seis colmos que em seguida eram divididos em cinco estacas de um metro de comprimento. Obtinham-se assim trinta estacas por tratamento. Desprezava-se um metro da base e a parte apical. Dessas trinta estacas, dez eram fendidas ao meio, no sentido longitudinal, para verificar o seu comportamento em relação às roliças. Cada tratamento (fases da lua) compreendia vinte estacas abertas e vinte roliças. Metade delas, eram enfeixadas e conservadas em galpão e a outra empregada na construção de uma cêrca.

Na cêrca, 10 estacas, sendo 5 abertas e 5 roliças, permaneciam elevadas $10 \mathrm{~cm}$ acima do nível do solo e as restantes do mesmo modo, tinham suas bases enterradas de $10 \mathrm{~cm}$.

Com o fito de se saber a influência de um preservativo de madeira sôbre a conservação do bambu, introduziu-se também um tratamento com tanalite (thanalith).

Para êsse fim, 20 estacas roliças e 20 fendidas, foram empregadas sendo matade de cada uma delas como acima mencionado, parte na cêrca e parte no galpão. O tratamento consistia em se mergulhar as estacas durante 15 minutos em um barril contendo uma solução a $2 \%$ de tanalite.

Muitos colmos, quando cortados, já mostravam a presença de insetos daninhos. Êsses eram sistemàticamente rejeitados. Procurou-se sempre escolher hastes maduras e livres de ciualquer presença de brocas.

O primeiro corte, foi efetuado a 18 de junho de $1947 ? 0$ último a 30 de dezembro de 1948 .

Observações constantes eram feitas, para acompanhar n comportamento do material e o início do aparecimento do ataque por insetos.

A distribuição do material colhido em cada fase da lua é mostrado nos quadros: I e II. 


\section{QUADRO I}

Conservados no galpão

\begin{tabular}{|c|c|c|}
\hline Tipo de estacas & Sem Tanalite & Com Tanalite \\
\hline $\begin{array}{l}\text { Roliças } \\
\text { Abertas }\end{array}$ & $\begin{array}{l}10 \\
10\end{array}$ & $\begin{array}{l}10 \\
10 \\
\end{array}$ \\
\hline
\end{tabular}

QUADRO II

Estacas empregadas na cêrca

\begin{tabular}{l|l|c|c}
\hline Modo de Aplicação & Tipo de Estacas & $\begin{array}{c}\text { Com } \\
\text { Tanalite }\end{array}$ & $\begin{array}{c}\text { Sem } \\
\text { Tanalite }\end{array}$ \\
\hline \multirow{3}{*}{ Eases suspensas } & Roliças & 5 & 5 \\
\multirow{2}{*}{ Bases enterradas } & Abertas & 5 & 5 \\
Roliças & 5 & 5 \\
Total & Abertas & 5 & 5 \\
\hline
\end{tabular}

\section{4 - DISCUSSÃO DOS RESULTADOS}

Pelos exames dos colmos conservados no galpão e os empregados na construção de cêrca, verificou-se que até janeiro nenhum dêles apresentava sinais de ataque por inseto. Posteriormente, a 16 de fevereiro de 1948, observou-se nas estacas conservadas no galpão e sem tanalite a existência de orifícios causados por brocas. Pelo levantamento feito, constatou-se que os lotes levemente atacados, foram colhidos nas seguintes fases da lua: cheia, em 29-9 e 29-10, minguante, 7-10 e 6-11, nova, 14-10 e 13-11 de 1947.

As estacas utilizadas na cêrca, se apresentavam sadias.

Em exames posteriores, nada mais se constatou de anormal, até 30 de dezembro de 1948, quando novos furos nos $\cdots$ lmos foram anotados nos lotes das seguintes fases: minguante: 1 de abril de 1948 e 27 de agosto de 1948; crescente: 25 de agosto de 1947 e 10 de outubro de 1948.

Pelas observações dos lotes, num total de 77 cortes, sendo 19 cortes para cada fase da lua, pôde-se observar que apenas 10 dos 77 cortes sofreram ação dos insetos, transcorrido ano e 
meio a partir do início dos trabalhos. Do número total de atacados por broca, estavam assim distribuidos, de acôrdo com os tratamentos: fase cheia 2 ; minguante 4 ; nova 2 e crescente 2

Êste número é reduzido, mesmo desprezível, se considerarmos que nem tôdas as estacas foram atingidas e as mais afetadas, foram as colhidas a partir de setembro, como pode ser observado no quadro III.

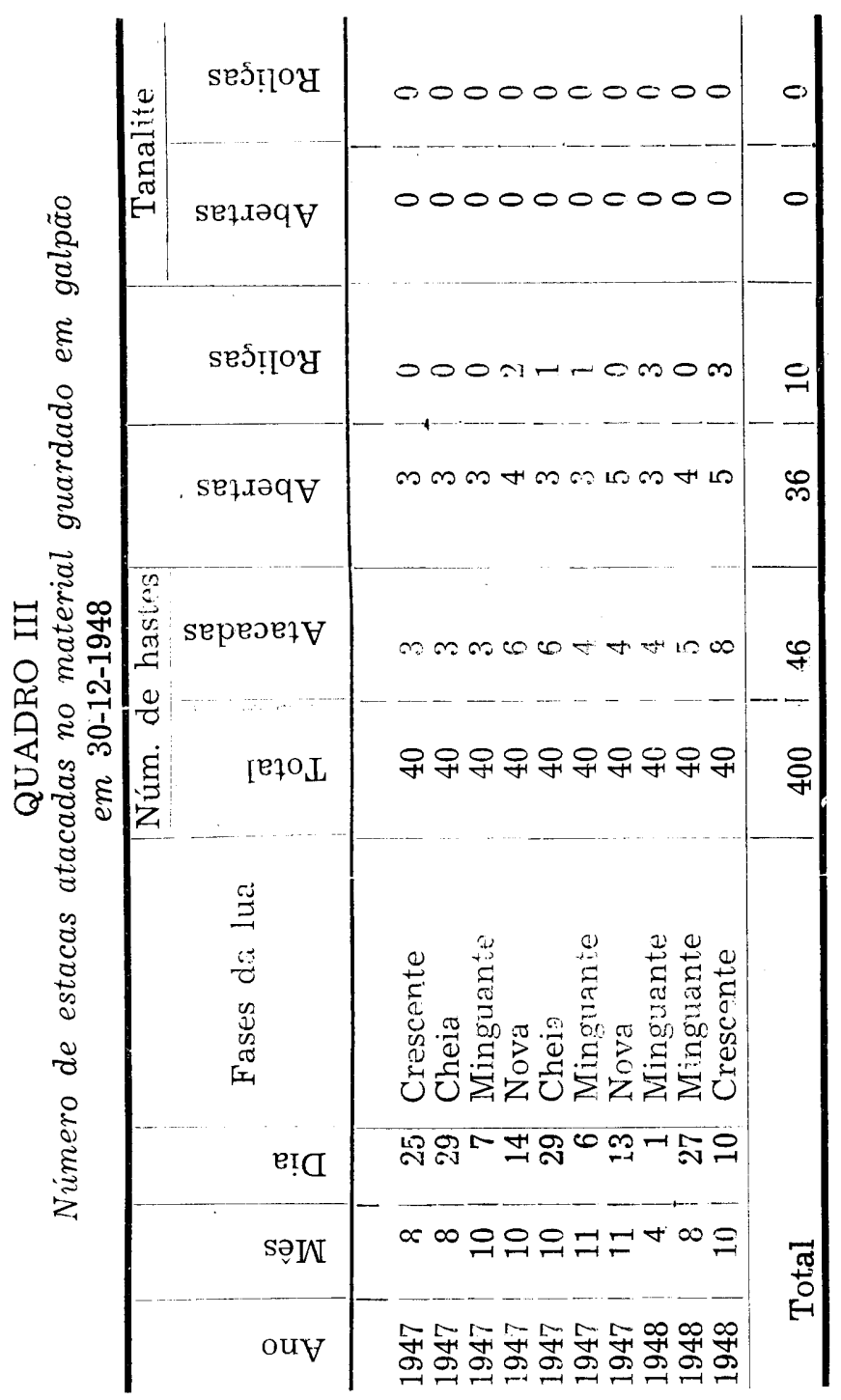


Como se pode notar, das 400 estacas, entre abertas, fechadas e tratadas com tanalite e conservadas no galpão, apenas 46 delas sofreram ataques, sendo 36 das abertas e 10 das roliças.

Se considerarmos o número total de estacas guardadas durante os 77 cortes, teríamos um total de 3.080 estacas, das quais apenas 46 foram afetadas até 30 de dezembro de 1948.

Os bambus utilizados para a construção da cêrca, tiveram melhor comportamento. A partir de fevereiro de 1949, notouse certo escurecimento, determinado talvez pelos fungos. Uma ou outra haste apresentava algum orifício causado por ataque de inseto. $\mathrm{O}$ número de perfurações era diminuto e encontrado em uma ou outra haste de quase todos os tratamentos. Esta cêrca permaneceu no local do ensaio até julho de 1950, quandr, para utilização do terreno ela foi retirada e transportada pard o galpão. Aí permaneceu por mais dois anos em bom estado de conservação. Inúmeros orifícios foram constatados, em todos os lotes sem distinção, exceção feita apenas aos tratados com tanalite, os quais resistiram melhor ao ataque dos insetos.

Em 1952, portanto, transcorridos cinco anos e meio do início do ensaio, tôdas as estacas se apresentavam em condições. senão ótimas, pelo menos satisfatórias para a utilização. As estacas que tiveram suas bases enterradas a $10 \mathrm{~cm}$ de profundidade, apresentavam sinais de decomposição naquela região, em julho de 1950, e muitas se encontram completamente desintegradas. Essa ação deletéria do solo foi generalizada, não havendo diferença alguma entre os tratamentos.

As estacas tratadas com tanalite, apresentaram uma maior durabilidade mas não tão significativa, pois se um grande número delas mantinha-se em bom estado de sanidade, outra parte apresentava também sinais de desagregação.

Comparando-se os bambus seccionados ao meio com os roliços, verificou-se que os não seccionados apresentavam mainr resistência à deterioração. De acôrdo com os trabalhos de PEREIRA (1948), CAMUS (1913), BEESON (1946) e SIMÃO (1957), é necessário, antes de qualquer conclusão responsabilizando a ação de certas fases da lua como mais favoráveis , u nefastas para o corte do bambu, ou de madeira, levar em consideração, o estado de desenvolvimento, estudo fisiológico do vegetal, sanidade da plantá no momento do corte, ciclo biológico dos insetos e sua população em determinado local. 


\section{5 - CONCLUSÕES}

Pelas observações feitas durante cinco anos e meio, as conclusões seguintes podem ser tiradas :

1) As fases da lua não influiram de modo algum sôbre a durabilidade das hastes de bambu, quer nas conservadas em galpão, como nas expostas ao tempo.

2) Pequeno ataque foi verificado em alguns poucos cortes, pertencentes a tôdas as fases da lua. O corte na fase minguante foi justamente o que apresentou o maior número de bambus afetados.

3) Os bambus que tiveram as bases enterradas no solo, sufreram decomposição, dessa parte, mais ou menos ràpidamente, bem que os abertos, arrissentaram menor resistência en reìação aos inteiriços.

4) O tratamento com tanalite, melhorou as condições de conservação dos bambus, principalmente dos abertos.

5) As estacas expostas às intempéries, foram menos aferadas pelos insetos, do que as conservadas em galpão.

\section{6 - ABSTRACT}

This paper brings to light new data on the absence of influence of lunar phases on the preservation of bamboo sticks. The author cut down for one and a half years (from - June 18, 1947 to December 30,1948$)$ bamboos in every phase of the moon. With part of the sticks obtained a fence was built; the rest was kept under shelter. In the fence there were: 5 whole sticiss with no preservative, 5 whole sticks with thanalith, 5 halved sticks with no preservative, 5 halved sticks with thanalith, a!l buried 10 centimeters in the soil. An equal number of the same types and in the same fence were kept upright 10 centimeters above the soil. Under shelter, in a shed, there was another group of sticks, 10 of each of the same four types. After 51/2 years no damage was observed in the fence for any treatment or any phase of the moon. On the other hand, for those bamboos kept under shelter the following numbers of perforated sticks were observed. 
Number of perforated sticks after $51 / 2$ years

\begin{tabular}{|c|c|c|c|c|c|}
\hline \multirow[b]{2}{*}{ Date of cutting } & \multirow[b]{2}{*}{$\begin{array}{c}\text { Phase of the } \\
\text { moon }\end{array}$} & \multicolumn{2}{|c|}{$\begin{array}{l}\text { Without } \\
\text { Thanalith }\end{array}$} & \multicolumn{2}{|c|}{ Thanalith } \\
\hline & & $\frac{0}{\stackrel{0}{0}} \frac{1}{3}$ & $\begin{array}{l}\bar{D} \\
\stackrel{D}{D} \\
\text { DI }\end{array}$ & $\begin{array}{l}\frac{9}{3} \\
\frac{9}{3}\end{array}$ & $\begin{array}{l}\text { D } \\
\stackrel{D}{7} \\
\mathbb{3}\end{array}$ \\
\hline $\begin{array}{r}8-25-47 \\
9-29-47 \\
10-7-47 \\
10-14-47 \\
10-29-47 \\
11-6-47 \\
11-13-47 \\
4-1-43 \\
8-27-48 \\
10-10-48 \\
\end{array}$ & $\begin{array}{l}\text { Prime } \\
\text { Full } \\
\text { Wane } \\
\text { New } \\
\text { Full } \\
\text { Wane } \\
\text { New } \\
\text { Wane } \\
\text { Wane } \\
\text { Prime }\end{array}$ & $\begin{array}{l}0 \\
0 \\
0 \\
2 \\
0 \\
3 \\
0 \\
3 \\
1 \\
1\end{array}$ & $\begin{array}{l}3 \\
3 \\
3 \\
3 \\
4 \\
5 \\
3 \\
1 \\
5 \\
3 \\
3 \\
\end{array}$ & $\begin{array}{l}0 \\
0 \\
0 \\
0 \\
0 \\
0 \\
0 \\
0 \\
0 \\
0\end{array}$ & $\begin{array}{l}0 \\
0 \\
0 \\
0 \\
0 \\
0 \\
0 \\
0 \\
0 \\
0 \\
\end{array}$ \\
\hline Totals & & 10 & 36 & 0 & 0 \\
\hline
\end{tabular}

So, among the 400 sticks kept under shelter, after $51 / 2$ years, only 46 were perforated, all among those withe no preservative. No influence of lunar phase at cutting down of sticks seems to be present.

\section{7 - BIBLIOGRAFIA}

ANONIMO, 1943 - O bambu, uma Máteria Prima de Utilidade Universal - A Fazenda: 38 (2): 65.

BEESON, C. F. C., 1946 - Forestry, Horticulture and the Moon. Forestry Abstracts, 8 (2): 191-198.

CAMUS, E. B., 1913 - Les Bambusees. Ed. Paul Lechevalier, pp. 1-215.

PEREIRA, J. A., 1949 - A Influência lunar na ação dos insetos. Anuário Brasileiro de Econômia Florestal, 2: 490-501. PUIG, I., 1942 - Influências Lunares. Ed. Sopena - B. Aires, pp. 1-198.

SIMÃO, S., 1953 - Contribuição ao Esstudo da Suposta Ação Lunar sôbre Plantas Hortícolas. Tese de Doutoramento, pp. 48. Piracicaba.

SIMÃO, S., 1957 - Crescimento do Bambu - Rev. de Agricultura, 32 (4) : 233-236.

TELES, O. A., 1922 - Apontamentos de Silvicultura - Sec. da Agricultura. São Paulo, pp. 124. 
